\title{
Positioning the Private Health Facilities Towards Continuous Service Provision During the COVID-19 Pandemic
}

\author{
Olayinka S. Ilesanmi ${ }^{12^{*}}$, Aanuoluwapo A. Afolabi ${ }^{1}$ \\ ${ }^{1}$ Department of Community Medicine, College of Medicine, University of Ibadan, Oyo State, Nigeria \\ ${ }^{2}$ Department of Community Medicine, University College Hospital, Ibadan, Oyo State, Nigeria
}

*Corresponding Author: Olayinka S. Ilesanmi, Ph.D., Instructor, Department of Community Medicine, College of Medicine, University of Ibadan, Oyo State, Nigeria. Tel: +234-8032121868, Email: ileolasteve@yahoo.co.uk

Received October 26, 2020; Accepted December 18, 2020; Online Published December 22, 2020

\begin{abstract}
The coronavirus disease 2019 (COVID-19) pandemic has triggered an increased demand for health services. Public health facilities are becoming increasingly inadequate to provide care for the increasing COVID-19 cases. Therefore, positioning the private health facilities (PHFs) to contribute to the COVID-19 outbreak response is highly required. To position PHFs for an improved COVID-19 outbreak response, guidelines that provide clarity on the role of PHF in the COVID-19 outbreak response need to be developed. Specific regulations should be tailored towards the government acting as a financial risk protector for PHF. Also, equity in the distribution of personal protective equipment (PPE) across the public and PHF from the Federal Government should be ensured. Moreover, subsidies should be provided on PPE, including goggles, hand sanitizers, and face masks. Furthermore, the purchase of PPE could be made by PHF on a large scale at subsidized costs via the PHF professional bodies and associations. Moreover, a comprehensive assessment of the human and infrastructural capacity of PHF needs to be conducted regarding the COVID-19 response. Results obtained from such assessment would inform on the existing human resources needs of the private sector and opportunities by which PHF's capacity could be enhanced. In addition, assessing the extent of representativeness of PHF in the existing rapid response team needs to be conducted. All challenges delimiting the active involvement of the PHF should be addressed. Additionally, adequate support systems need to be developed and well-placed to promote the involvement of the PHF in the outbreak response.

Keywords: Coronavirus, Private Sector, Public-Private Partnership, Disease Outbreaks, Access to Health Services
\end{abstract}

\section{Background}

The coronavirus disease 2019 (COVID-19) pandemic has triggered an increased demand for health services. ${ }^{1-3}$ A noteworthy response to this demand is the increasing urgency for testing, tracing, treating, and isolating COVID-19 positives while maintaining the continual provision of healthcare. ${ }^{1,4}$ However, public health facilities are becoming increasingly inadequate to cater for the increasing COVID-19 cases. ${ }^{5,6}$ The PHFs account for 33\% of health facilities in Nigeria and cater for nearly a third of the population mainly at the secondary healthcare level. ${ }^{7}$ Profound results have been obtained on the involvement of PHF in many health-related events, including Ebola, measles, polio, malaria, youth-friendly services, etc. ${ }^{8-}$ ${ }^{11}$ In spite of existing laudable successes, PHFs are being underutilized in the ongoing COVID-19 outbreak response. Therefore, positioning the PHF to contribute to the COVID-19 outbreak response is a necessity.
2. The Relevance of PHFs Amid the COVID-19 Pandemic Nigeria reported her index case of COVID-19 on the $27^{\text {th }}$ February, 2020. ${ }^{12-14}$ Since this period, the infection rate has spiraled to 73175 cases as of $21^{\text {st }}$ December, $2020 .^{15}$ Also, 1197 fatalities have been associated with the COVID-19 infection as of the reference period..$^{15}$ The Nigerian government has taken responsive actions towards engaging a multi-sectoral approach in the COVID-19 response, with the health sector centrally positioned., ${ }^{9,16}$ This has included the approval of COVID-19 testing and isolation of COVID-19 cases in designated private health facilities (PHFs), a number of which are widely distributed across the thirty-six states of the Federation and the Federal Capital Territory, Abuja. ${ }^{17}$ These have enhanced COVID-19 sample collection, testing, result turn-out rate, and management of COVID-19 positives. Private sector involvement has been of immense benefit to individuals with short travel notices who are required to provide COVID-19 certificates at the airport. Unfortunately, the

Copyright (C) 2020 The Author(s). This is an open-access article distributed under the terms of the Creative Commons Attribution License (http:// creativecommons.org/licenses/by/4.0), which permits unrestricted use, distribution, and reproduction in any medium, provided the original work is properly cited. 
huge cost associated with health-seeking at PHF is a major challenge being faced in the COVID-19 dispensation. This, therefore, identifies the need for increased government support for PHF.

\section{Opportunities for Positioning PHF for an Improved Response Amid the COVID-19 Pandemic}

Presently, guidelines for the involvement of PHF in the COVID-19 outbreak response are unavailable in Nigeria. To position PHF for an improved COVID-19 outbreak response, guidelines that provide clarity on the role of PHF in the COVID-19 outbreak response need to be developed. The specifications on the guidelines should include patient risk assessment and triaging mode of sample collection, sample storage, requirements in biosafety level, mode of COVID-19 result disclosure, isolation equipment, frequency of re-testing, treatment modalities using the approved anti-malarial medications, the required minimum number of skilled and unskilled health personnel, and duty schedule. The availability of these guidelines would provide adequate information on the requirements to be met before PHF could be enrolled to partake in the response activities. Knowledge of such guidelines would enhance scaling-up in PHF where deficiencies exist. At the same time, the capacity of PHF needs to be enlarged through the decentralization of COVID-19 testing centers and the allocation of COVID-19 isolation centers to PHF who meet the requirements for accommodating COVID-19 confirmed cases. ${ }^{18}$

The PHF are for-profit organizations, therefore specific regulations should be tailored towards the government acting as a financial risk protector for PHF. For instance, health loans should be made available to PHF who are willing to partake of the COVID-19 response activities where capacities to return such loans exist within the stipulated time. Also, a logical conclusion should be reached between the federal government and designated PHF on the mode of sharing income generated by each COVID-19-centred activity. The COVID-19 outbreak has been associated with a PPE such as face masks, alcoholbased hand rubs, goggles, and face shields. ${ }^{19}$ To enable the contribution of PHF to the COVID-19 response, equity in the distribution of PPE across the public, and PHF from the federal government should be ensured. Meanwhile, subsidies should be provided on PPE, including goggles, hand sanitizers, and face masks. This would enhance private sector involvement in the COVID-19 outbreak response, and also reduce the risk of engaging in COVID-19 patient care secondary to PPE inadequacy. Meanwhile, the purchase could be made by PHF on a large scale at subsidized costs through the PHF professional bodies and associations.

As part of the joint health workforce, practitioners in PHF should be involved in requisite infection prevention and control (IPC) training. This posits the need for their involvement in the attendance at such IPC training similar to their counterparts in the public health facilities.
The training of trainers should also adequately involve practitioners at PHF to ensure that knowledge gained from such pieces of training have an impact on other staff at their facilities. Also, modalities of risk assessment, triaging, handling of COVID-19 cases, and management of confirmed cases of COVID-19 should be taught through organized training for practitioners in public and $\mathrm{PHF}^{20}$ Rather than sticking to the traditional physical training, some of these could be held virtually on online platforms such as WhatsApp, Telegram, Zoom, and Blue Jean. The adoption of virtual means overcomes the challenge of transportation to physical meeting venues and enhances attendance on a large scale especially among PHF. It should however be noted that omission in the practicality of knowledge gained from COVID-19-focused training in the management of COVID-19 positives should attract corrections and sanctions which should be equally served across public and PHF. Also, commendations should be awarded for optimal management of COVID-19 positives. These, therefore, bridge the gap between practitioners at public and PHF foundations.

Moreover, a comprehensive assessment of the human and infrastructural capacity of PHF needs to be conducted regarding the COVID-19 response. Results obtained from such assessment would inform on the existing human resources needs of the private sector and opportunities by which PHF's capacity could be enhanced for an effective national outbreak response, as well as raising data quality. A 2011 private sector assessment in Ghana revealed fragmentation as a major challenge to health delivery due to the involvement of a wide range of players, including individuals, professional groups, and sub-groups. ${ }^{21}$ Results obtained therefore explained the poor health data quality obtained in Ghana during the reference period. Drawing on lessons learnt from the Ghana experience, registered professional groups should be represented in public-private sectors' engagement during the COVID-19 outbreak response in Nigeria to improve harmonious relationship between the professional groups. Meanwhile, such comprehensive assessment would foster interdisciplinary action amid the groups as required for an improved outbreak response.

Furthermore, assessing the extent of representativeness of PHF in the existing rapid response team needs to be conducted. In areas where adequate representativeness of the private sector is lacking, the inclusion of stakeholders in the PHF needs to be considered. ${ }^{1}$ This, therefore, implies that the COVID-19 response is a joint responsibility for which total control does not lie with any single sector. ${ }^{22-26}$ When PHF are adequately represented, feuds and distrust in the modality of task execution are overcome. ${ }^{27-29}$ In addition, the adequate representativeness of the private sector would be required to enhance feedback from community members who access both private and public facilities for currently-implemented COVID-19 outbreak response measures. ${ }^{30,31}$ The quality of knowledge acquired on these grounds would promote decision-making 
regarding the successes and failures of these measures, and help to adequately plan new interventions or improve existing ones. ${ }^{32-34}$

\section{Conclusion}

The COVID-19 outbreak has placed great demands on the Nigerian health system. However, the COVID-19 outbreak has explicitly highlighted the need for public-private collaboration in the outbreak response. Positioning PHF aright becomes promising for an improved COVID-19 outbreak response in Nigeria. All challenges delimiting the active involvement of the PHF should be addressed. Moreover, adequate support systems need to be developed and well-placed to promote the involvement of the PHF in the outbreak response. In addition, PHF must be adequately involved in relevant health projects. This will build positive relationships between the public and PHF and a sense of togetherness which will enable a timely and adequate response to the current COVID-19 outbreak or future pandemics. Adequate involvement of PHF will also reduce wastage of resources attributed to the sole management of health projects by public stakeholders. Similarly, the involvement of PHF will overcome the barriers associated with the complexities of accessing care in public health facilities. The involvement of PHF also prevents the deprivation of accessing care among individuals who would not seek COVID-19 care at public health facilities.

\section{Authors' Contributions}

OSI conceptualized the research, while AAA and OSI wrote the initial draft of the manuscript and revised it for critical intellectual content, and approved the final version.

\section{Conflicts of Interest Disclosures}

The authors declare no conflicts of interest

\section{Ethical Approval}

Not applicable.

\section{References}

1. Ilesanmi OS, Afolabi AA. In search of the true prevalence of COVID-19 in Africa: time to involve more Stakeholders. Int J Health Life Sci. 2020;e108105. doi:10.5812/ijhls.108105.

2. Ilesanmi OS, Olabumuyi OO, Afolabi AA. Mobilizing medical students for improved COVID-19 response in Nigeria: a stop gap in human resources for health. Global Biosecurity. 2020;1(4). doi:10.31646/gbio.89.

3. Ilesanmi OS, Olaleye OO, Afolabi AA. Keeping in-school adolescents safe from COVID-19 sequel to the suspension of school lockdown restriction. Global Biosecurity. 2020;2(1). doi:10.31646/gbio.96

4. Ilesanmi OS, Akande A, Afolabi AA. Overcoming COVID-19 in West African countries: is herd immunity an option? Pan Afr Med J. 2020;35(Suppl 2):103. doi:10.11604/pamj. supp.2020.35.2.24217.

5. Ilesanmi OS, Afolabi AA, Fakayode OE. Patent medicine vendors' preparedness and response for the prevention and control of COVID-19 infection in a North-central state in Nigeria. Int J Pharm Pharm Sci. 2020;12(12):80-84. doi:10.22159/ijpps.2020v12i12.40097.

6. Ilesanmi OS, Oguntoye AA, Afolabi AA. The new norm in the management of COVID-19 positives: home-based care. Journal of Ideas in Health. 2020;3(4):252-253. doi:10.47108/jidhealth. Vol3.Iss4.78.

7. Makinde OA, Sule A, Ayankogbe O, Boone D. Distribution of health facilities in Nigeria: implications and options for Universal Health Coverage. Int J Health Plann Manage. 2018;33(4):e1179-e1192. doi:10.1002/hpm.2603.

8. Walker PG, White MT, Griffin JT, Reynolds A, Ferguson NM, Ghani AC. Malaria morbidity and mortality in Ebola-affected countries caused by decreased health-care capacity, and the potential effect of mitigation strategies: a modelling analysis. Lancet Infect Dis. 2015;15(7):825-832. doi:10.1016/s14733099(15)70124-6.

9. World Health Organization (WHO). Malaria Case Management in the Private Sector: Conclusions Reached During the MPAC Meeting of 11-13 September 2012. WHO; 2012.

10. Akhter N, Ali A, Nelson D, et al. Implementing Youth-friendly Health Services in Public-Private Settings: A Health System Improvement Initiative. Presented at: 2th Annual Scientific Conference (ASCON XII) Health Systems Research: People's Needs First; 2009.

11. Barden-O'Fallon J, Evans S, Thakwalakwa C, Alfonso W, Jackson A. Evaluation of mainstreaming youth-friendly health in private clinics in Malawi. BMC Health Serv Res. 2020;20(1):79. doi:10.1186/s12913-020-4937-9.

12. Nigeria Centre for Disease Control (NCDC). First Case of Coronavirus Disease Confirmed in Nigeria. NCDC; 2020.

13. Ilesanmi OS, Afolabi AA. Six months of COVID-19 response in Nigeria: lessons, challenges, and way forward. Journal of Ideas in Health. 2020;3(Special 1):198-200. doi:10.47108/jidhealth. Vol3.IssSpecial1.63.

14. Ilesanmi OS, Ariyo M, Afolabi AA. Domesticated c violence amid the COVID-19 lockdown: a threat to individual safety. Global Biosecurity. 2020;2(1). doi:10.31646/gbio.94

15. European Centre for Disease Prevention and Control (ECDC). COVID-19 Situation Update Worldwide, As of Week 50, 2020. https://www.ecdc.europa.eu/en/geographical-distribution2019-ncov-cases). Published 2020. Accessed December 21, 2020

16. United Nations Development Programme (UNDP). COVID-19 Pandemic: Humanity Needs Leadership and Solidarity to Defeat COVID-19. Nigeria: UNDP; 2020. https://www. ng.undp.org/content/nigeria/en/home/coronavirus.html?cq $c k=1587691488777$. Accessed October 26, 2020.

17. Adediran I. Lagos Govt Approves Seven Private Laboratories for COVID-19 Testing. Premium Times; 2020. https://www. premiumtimesng.com/regional/ssouth-west/400305-lagosgovt-approves-seven-private-laboratories-for-covid-19-testing. html. Accessed October 262020

18. Ilesanmi OS, Afolabi AA. Time to move from vertical to horizontal approach in our COVID-19 response in Nigeria. SciMed J. 2020;2:28-29. doi:10.28991/SciMedJ-2020-02-SI-3.

19. Ilesanmi OS, Afolabi AA. Perception and practices during the COVID-19 pandemic in an urban community in Nigeria: a cross-sectional study. PeerJ. 2020;8:e10038. doi:10.7717/ peerj.10038.

20. Ilesanmi OS, Afolabi AA. A scope review on home-based care practices for COVID-19: what Nigeria can learn from other countries. Ibom Med J. 2021;14(1):1-9.

21. Mensah S, Ameyaw C. Sustainable Procurement: The Challenges of Practice in the Ghanaian Construction Industry. Abuja, Nigeria: West Africa Built Environment Research (WABER); 2012.

22. Private Sector's Role in Mitigating the Impact of COVID-19 on Vulnerable Women and Girls in Nigeria. United Nations 
Nigeria website. https://nigeria.un.org/en/43767-privatesectors-role-mitigating-impact-covid-19-vulnerable-womenand-girls-nigeria. Published 2020.

23. FMN Food and Agro-Allied Group. See how We are Mobilizing Our Resources to Help Nigeria Find Solutions for COVID-19. (Accessed December 212020 at: https://www.fmnplc.com/ covid-19/index.html\#findingSolution).

24. Crucial Supplies Contribute to COVID-19 Response in Nigeria. UNICEF Nigeria website. 2020. https://www.unicef.org/ nigeria/press-releases/crucial-supplies-contribute-covid-19response-nigeria. Published 2020.

25. CA-COVID. Private Sector Coalition Against COVID-19. Coalition Against COVID-19(CACOVID); 2020. https://www. cacovid.org/.

26. Gender and the COVID-19 National Response in Nigeria. UN Women Africa website. https://africa.unwomen.org/en/digitallibrary/publications/2020/04/brief-gender-and-the-covid-19national-response-in-nigeria. Published 2020.

27. The Guardian. Preparing Private Sector for Next Pandemic. The Guardian. November 15, 2019. https://guardian.ng/features/ health/preparing-private-sector-for-next-pandemic/.

28. Onyekwena C, Ekeruche MA. Understanding the Impact of the COVID-19 Outbreak on the Nigerian Economy. Brookings. 2020. https://www.brookings.edu/blog/africa-infocus/2020/04/08/understanding-the-impact-of-the-covid-19outbreak-on-the-nigerian-economy/.
29. Chen C. COVID-19: Private Sector's Role in Times of Crisis RSIS Commentary No. 051 (26 March 2020). https://reliefweb. int/report/world/covid-19-private-sector-s-role-times-crisis-rsiscommentary-no-051-26-march-2020. Published 2020.

30. Salaudeen A. Government, Banks and Wealthy Individuals Contribute Billions to Fight Coronavirus in Nigeria. Marketplace Africa.2020. https://edition.cnn.com/2020/03/27/ africa/coronavirus-nigeria-fund/index.html.

31. Aworinde T. COVID-19: Nigeria's Second Wave Imminent, Says Minister. MSN. 2020. https://www.msn.com/en-xl/ africa/nigeria/covid-19-nigerias-second-wave-imminent-saysminister/ar-BB1 azTdZ

32. Binagwaho A, Mathewos K. What Explains Africa's Successful Response to the COVID-19 Pandemic? Medical News Today. 2020. https://www.medicalnewstoday.com/articles/ what-explains-africas-successful-response-to-the-covid-19pandemic.

33. Africa.com. An Urgent Call for Sustainable Healthcare Reforms in Africa Amidst the COVID-19 Crisis. https://africa.com/ an-urgent-call-for-sustainable-healthcare-reforms-in-africaamidst-the-covid-19-crisis/. Accessed December 212020

34. Ejiogu A, Okechukwu O, Ejiogu C. Nigerian budgetary response to the COVID-19 pandemic and its shrinking fiscal space: financial sustainability, employment, social inequality and business implications. J Public Budg Account Financial Manag. 2020;32(5):919-928. doi:10.1108/jpbafm-07-2020-0101 